\title{
CONNECTING PROCESS MODELS OF TOPOGRAPHIC WAVE DRAG TO GLOBAL EDDYING GENERAL CIRCULATION MODELS
}

By Brian K. Arbic, Oliver B. Fringer, Jody M. Klymak,

Frederick T. Mayer,

David S. Trossman, and Peiyun Zhu

\begin{abstract}
This paper focuses on the representation of damping of mesoscale eddies, currents, and tides in global ocean models by the topographic wave drag they generate over bathymetric features. Insertion of parameterized topographic wave drag into global high-resolution models strongly impacts the energy budget, near-bottom stratification, near-bottom velocities, and vertical structure of low-frequency mesoscale eddies and currents, and impacts the low-frequency surface kinetic energy and sea surface height variance to a measurable (though lesser) extent. Parameterized topographic wave drag also strongly impacts the amplitudes of tidal motions. Process modeling studies show great potential to improve existing topographic wave drag parameterizations, although much more work is needed to develop a complete understanding of the full parameter space needed to develop practical implementations for global ocean models.
\end{abstract}

IN PLAIN WORDS. Underwater bottom features, including seamounts, ridges, abyssal hills, and the slope of the seafloor from the bottom to the coast, strongly affect ocean currents. These bottom features are called topography, and when currents flow over them, turbulence and waves that are trapped within the ocean (internal waves) are generated. Similar turbulence and trapped waves occur when air currents flow over mountains, creating turbulence and waves that jostle air travelers. Creating internal waves uses up some of the energy in the currents. Thus, wave creation acts like a drag on the ocean currents, changing their speed and structure. Here, we review studies that use theory and computer modeling to better understand the detailed small-scale physics behind this drag in order to improve approximations of wave drag for use in ocean models that forecast currents. We also review the impacts of currently existing wave drag approximations on the ocean forecast models.

\section{INTRODUCTION}

This paper is about (1) process studies of topographic wave drag, the drag due to the generation of internal gravity waves (IGWs) and low-level hydraulic effects and turbulence (also known as blocking) by flows over topographic features, and (2) the impact of topographic wave drag parameterizations, developed from such process studies, on eddies, currents, and tides in global high-resolution eddying oceanic general circulation models (OGCMs). IGWs are waves in a stratified fluid for which the restoring force is gravity. Figure 1 illustrates IGWs and blocking in a process model of steady flow over topography that is tall enough to produce blocking effects. The drag due to IGWs and blocking is often denoted as "propagating" and "non-propagating" drag, respectively, in the literature. This paper focuses primarily on IGWs, blocking, and topographic wave drag (hereafter, often shortened to "wave drag") by low-frequency flows such as currents and mesoscale eddies; some attention is given to the related problem of wave drag on tidal motions. IGWs generated by low-frequency flows are often referred to as "lee waves." 
With increased supercomputer power, several institutions around the world now run global OGCMs at "eddying" horizontal resolutions-that is, horizontal resolutions high enough (about $1 / 10^{\circ}$ or finer) to maintain a vigorous field of mesoscale eddies, the oceanic dynamical counterparts to atmospheric weather systems. Mesoscale eddies typically have timescales of about 10-200 days and horizontal length scales of roughly $100 \mathrm{~km}$. The United States Navy uses the HYbrid Coordinate Ocean Model (HYCOM) as the backbone hydrodynamical core of its global prediction system (Chassignet et al., 2009). The Navy Coupled Ocean Data Assimilation system (NCODA; Cummings, 2005) incorporates in situ and remotely sensed observations of sea surface temperature, sea surface height, and temperature and salinity into global HYCOM forecasts. In recent years, some HYCOM simulations have begun to incorporate tidal forcing and forcing from atmospheric fields simultaneously (Arbic et al., 2018, and references therein).

There are several ways in which flow-topography interactions that impose drag on the underlying flow, the subject of the Flow Encountering Abrupt
Topography (FLEAT) field program discussed by Johnston et al. (2019) and others in this special issue, have been employed in global HYCOM simulations. The simplest is quadratic bottom boundary layer drag (Taylor, 1919; hereafter, often called "quadratic bottom drag"), which is proportional to the square of the flow velocity and to a drag coefficient that is typically kept constant throughout the spatial domain of global ocean models. However, the seafloor varies greatly from one oceanic region to the next, due to features such as seamounts, abyssal hills, shelf breaks, dunes, and coral reefs, calling into question whether the drag used in models should be constant in space. When currents, eddies, or tides encounter topographic features, they generate IGWs (Bell, 1975). Most of the energy dissipation and mixing in the open ocean interior is due to the breaking of IGWs (e.g., Waterhouse et al., 2014; Kunze, 2017), which creates drag on the momentum of oceanic flows. Flows over rough bathymetry also produce blocking and low-level turbulence (Figure 1). The importance of large-scale blocking has long been appreciated by atmospheric scientists, who tend to separate lee wave drag into a linear drag due to the production of lee waves and a drag due to nonlinear blocking (hydraulic) effects (e.g., Pierrehumbert, 1987). For the blocking component, the typical approach has been to assume that obstacles are isolated and three-dimensional, leading to a bluff-body form drag scaling that is proportional to the square of the background flow; this scaling is used in most atmospheric science and climate modeling literature (Lott and Miller, 1997; Scinocca and MacFarlane, 2000). Recent work suggests that blocking effects may be important or even dominant in some regions of the ocean (e.g., Thurnherr and Speer, 2003; Trossman et al., 2015; Dossmann et al., 2016).

The parameterized wave drag employed in HYCOM simulations of either low-frequency flows or tides is applied to the bottom $500 \mathrm{~m}$, a rough vertical scale for internal wave motions (St. Laurent et al., 2002). The earliest HYCOM tidal simulations employed a "scalarized" version of a tensor drag, based upon linear analysis, that is linear in the background velocity (Garner, 2005), but altered by a scalar constant, derived from dimensional reasoning

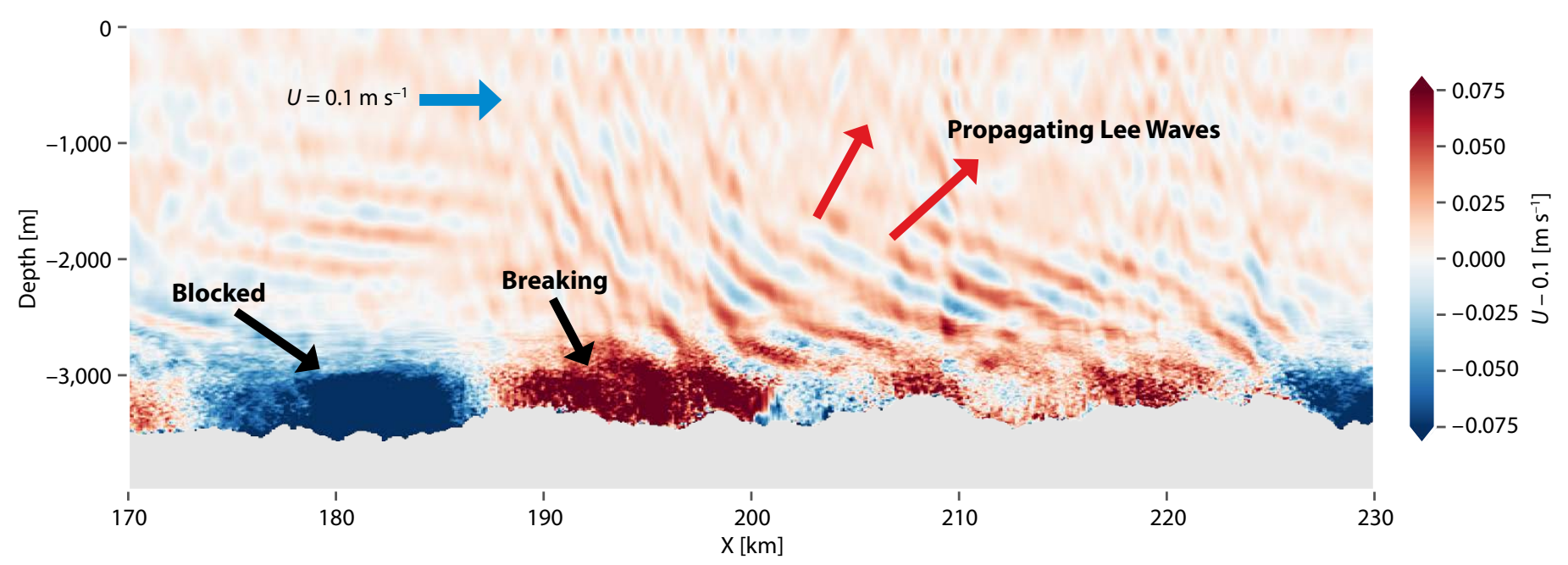

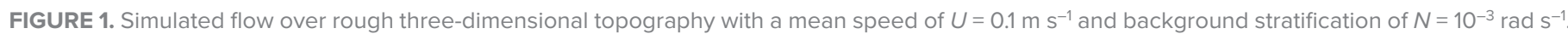

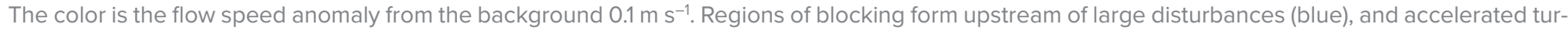

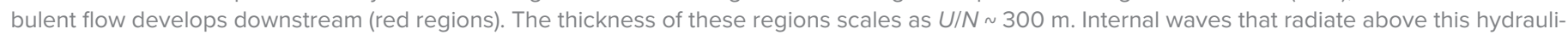
cally dominated region from small-scale features are particularly enhanced where the flow has been accelerated. Adapted from Klymak (2018) 
following Pierrehumbert (1987) and related work, that accounts for blocking effects. In the full Garner (2005) formulation, the full tensor drag is obtained through multiplication of a tensor (matrix) by the flow velocity. The presence of off-diagonal terms in the tensor yields a drag that is not exactly opposite the flow velocity. In the scalarized version of the drag, we remove the offdiagonal components and set both diagonal components equal to the average of the two, yielding a drag that is exactly opposite the flow velocity. Although both tides and low-frequency currents and eddies generate IGWs, the rate at which they do so differs, so classical theories such as Bell (1975) treat oscillatory and steady flows as limiting cases. Because of these differences, in our HYCOM simulations with tides, the tidal flows are separated from the low-frequency flows with a 49-hour high-pass filter, and wave drag is restricted to the tidal component of the flow. Because errors in the filtering routine can lead to artificially large lowfrequency currents (Arbic et al., 2010), the parameterized wave drag needs to be clipped with a threshold value (Shriver et al., 2012). Recent HYCOM simulations with tides (beginning with Ansong et al., 2015) employ the simpler wave drag scheme of Jayne and St. Laurent (2001). HYCOM simulations with parameterized wave drag on eddies and currents (Trossman et al., 2013, 2016, 2017) employed the Garner (2005) scheme and did not include explicit tides, in order to avoid the complications associated with tide/low-frequency current splitting described above. See Olbers and Eden (2017) and Eden and Olbers (2017) for a related effort at implementing wave drag in circulation models that is part of an ambitious project on mixing parameterizations described in Olbers et al. (2019).

Most of the small horizontal topographic scales that generate IGWs are not resolved by even the best available global bathymetry products, such as the Smith and Sandwell (1997) data set and its descendants. Goff and Arbic
(2010) developed models that represented unresolved small-scale abyssal hill topography with parameterized spectra that can account for small-scale topography in much of the ocean floor (e.g., see Figure 5 of Goff and Arbic, 2010; see also Goff, 2010). Trossman et al. (2013, 2016) used these spectra to generate fields for their wave drag scheme. The Goff spectra, and realizations of the spectra in the spatial domain, have also been used in Scott et al. (2011), Melet et al. (2013), and Timko et al. (2017).

In the following sections we describe the impact of parameterized topographic wave drag and quadratic bottom drag on low-frequency flows and tides in process study models and realistic global models. We then describe process models of topographic wave drag and the improvements to future wave drag parameterizations that will result from these process models.

\section{IMPACT OF PARAMETERIZED WAVE DRAG ON LOW- FREQUENCY FLOWS}

The parameterized drag inserted into both idealized and realistic models of eddies affects eddy amplitudes and other characteristics. For example, Arbic and Flierl (2004), Arbic et al. (2007), and Arbic and Scott (2008) demonstrated that the amplitudes, horizontal length scales, and vertical structures of eddies in idealized two-layer, flat-bottom quasigeostrophic (QG) turbulence lie closer to observations when bottom drag is moderately strong. The argument holds whether the bottom drag is linear, as in Arbic and Flierl (2004) and Arbic et al. (2007), or quadratic, as in Arbic and Scott (2008). Thompson and Young (2006) provided a scaling argument for the sensitivity of idealized QG turbulence to bottom drag. The impact of bottom drag on QG turbulence is related to strong transfers of energy between different length scales. In three-dimensional turbulence, nonlinearities drive kinetic energy toward smaller scales, in the so-called forward cascade. In two-dimensional turbulence, nonlin- earities instead effect an "inverse cascade" of kinetic energy toward larger horizontal scales. Because vertical motions in QG systems are weak compared to horizontal motions, QG turbulence behaves much like two-dimensional turbulence. In the weak bottom drag limit of flat-bottom QG turbulence, flows have little vertical structure and are therefore close to the twodimensional limit, with a vigorous inverse kinetic energy cascade. In the strong bottom drag limit, flows are surfaceintensified and weak at the bottom, and thus experience an inverse cascade in potential rather than kinetic energy. Oceanic eddies appear to be in between these extremes; spectral calculations from satellite altimeter data (Scott and Wang, 2005) indicate an inverse kinetic energy cascade that is ubiquitous in the ocean, but that does not proceed across a large range of scales as one might expect from the weak bottom drag limit of QG turbulence.

Power dissipation of low-frequency flows by quadratic bottom drag in the ocean was found to be in the range of 0.2-0.8 terrawatt (TW; Sen et al., 2008; Arbic et al., 2009), a significant fraction of the wind input into the general circulation. Pearson et al. (2017) demonstrated that eddying global simulations employing scale-aware subgrid-scale parameterizations for horizontal mixing of momentum and tracers show a larger amount of dissipation by quadratic bottom drag than simulations that employ the standard biharmonic horizontal mixing. The Pearson et al. results demonstrate the important role of model numerics in estimates of dissipation made from ocean models.

Trossman et al. (2013, 2016, 2017) examine the impact of parameterized topographic wave drag and quadratic bottom boundary layer drag on the eddying general circulation in HYCOM. Trossman et al. (2013, 2016) demonstrate that wave drag dissipates about 0.4 TW, a substantial fraction of the wind power input, primarily in regions where currents and eddies are strong and the bathymetry is rough. The Southern 
Ocean is a particular "hotspot" of dissipation by wave drag (Figure 2). Trossman et al. (2013) demonstrate that the stratification in the bottom $500 \mathrm{~m}$ is significantly reduced in simulations with wave drag, and Trossman et al. (2013, 2016) show that the eddy kinetic energy in the bottom $500 \mathrm{~m}$ is strongly reduced when wave drag is introduced. The reduction in bottom kinetic energy with wave drag is especially strong (59\%) in HYCOM simulations run at $1 / 25^{\circ}$, but is still substantial $(19 \%)$ in $1 / 12.5^{\circ}$ HYCOM simulations. Trossman et al. (2016) suggest that the regions where bottom kinetic energy increases with the introduction of wave drag are locations where the flow adjusts to nearby topographic blocking effects. The introduction of wave drag also causes changes in the surface ocean, far above where wave drag is introduced in the model; globally averaged mesoscale eddy sea surface height variance and surface kinetic energy are reduced by $15 \%-23 \%$ in $1 / 12.5^{\circ}$ and $1 / 25^{\circ}$ HYCOM simulations with wave drag, a reduction that goes beyond the level of seasonal vari- ability in these quantities.

Parameterized wave drag has a much stronger effect than quadratic bottom drag-even quadratic bottom drag that has a drag coefficient increased artificially by a factor of 100 - on the baroclinicity, or vertical structure, of low-frequency flows in HYCOM (Trossman et al., 2017). The increased baroclinicity seen with wave and quadratic bottom drag in HYCOM is qualitatively similar to that seen in idealized flat-bottom QG turbulence simulations, described earlier. However, Trossman et al. (2017) show that adding wave drag or an artificially strong quadratic bottom drag into HYCOM does not significantly change the horizontal scales of eddies. Trossman et al. (2017) find that eddy horizontal scales in two-layer QG turbulence simulations with a rough bathymetry are also relatively insensitive to the strength of bottom drag, and hence argue that the presence of rough bathymetry reduces the sensitivity of eddy horizontal scales to quadratic bottom drag or wave drag, consistent with results from the HYCOM simulations.

\section{IMPACT OF PARAMETERIZED WAVE DRAG ON TIDES}

Wave drag also affects tides. Barotropic (depth-averaged) tidal flow over rough bathymetric features generates internal tides (IGWs of tidal frequency). Bathymetry with large (small) horizontal scales generates internal tides with large (small) horizontal scales. The internal tides with small horizontal scales tend to dissipate near their generation sites, whereas internal tides with large horizontal scales tend to propagate for thousands of kilometers before dissipating (e.g., Alford and Zhao, 2007). We have long argued that the barotropic and baroclinic tides in global models will tend to be too large if the models omit explicit damping terms meant to parameterize, however crudely, breaking of unresolved small-scale internal tides. For example, Ansong et al. (2015) demonstrate that the sea surface height signature of stationary internal tides is too large, relative to altimetry, in HYCOM tidal simulations without any extra explicit drag; more recent work led by Joseph Ansong,

\section{Base-10 Logarithm of Wave Drag Dissipation $\left[\mathrm{W} \mathrm{m}^{-2}\right]$}

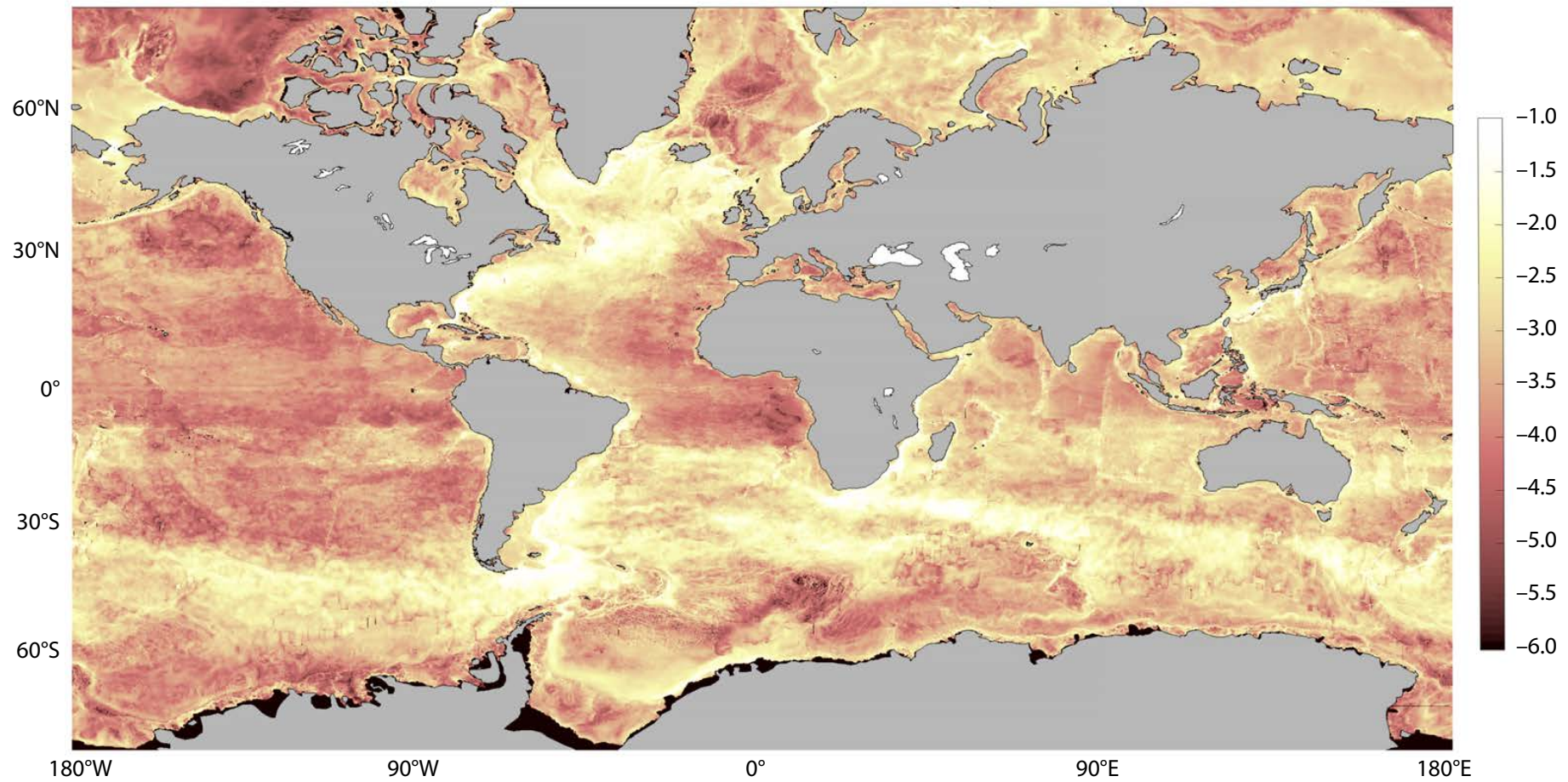

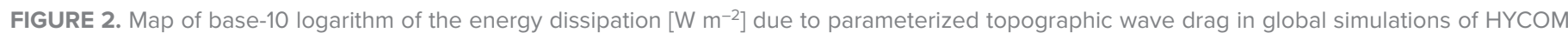
run at $1 / 25^{\circ}$ horizontal resolution, without explicit tides. Adapted from Figure 1 of Trossman et al. (2016) 
University of Ghana, demonstrates that several other global models display similar behaviors. The energy budget of internal tides (Buijsman et al., 2016), and the magnitudes of surface tidal velocities (recent work led by Jonathan Brasch, University of Michigan), are also found to be strongly impacted by parameterized wave drag.

\section{PROCESS MODEL RESULTS OF STEADY FLOWS OVER TOPOGRAPHY}

Linear Lee Wave Theory

Abyssal hill bathymetry, which consists of a spectrum of length scales, can be simplified by assuming that it is comprised of a single component of the power spectrum, that is, as a simple sinusoid with trough to crest height $h$ and length $L_{\text {hill }}$ with wavenumber $\mathrm{k}=2 \pi / L_{\text {hill }}$ aligned perpendicular to the background flow that has velocity $U$ and buoyancy frequency $N$. Under these assumptions, the behavior of abyssal lee waves is governed by the dimensionless parameters $J=N h / U$ and $\varepsilon=U k / N$. The nonlinearity is characterized by $J$, a Froude number relating the perturbation velocity of the lee wave, $\mathrm{Nh}$, to the group velocity of the lee wave in a reference frame moving with the fluid, $U$ (Mayer and Fringer, 2017). The second parameter, $\varepsilon$, relates the wavelength of the lee wave, $\lambda_{\text {lee }}=2 \pi U / N$, to the length of the bathymetry, $L_{\text {hill }}=2 \pi / k$, and can be viewed as a measure of the nonhydrostasy of the topography, with the hydrostatic limit given by $\varepsilon<<1$. For this idealized lee wave, the drag $F_{\text {lin }}$ (in units of force per unit spanwise width) predicted by linear theory $(J<<1)$ is given by

$F_{\text {lin }}=\frac{1}{4} \rho_{0} \pi U N h^{2}\left(1-\varepsilon^{2}\right)^{\frac{1}{2}}=\frac{\pi}{4} F_{0} J^{2}\left(1-\varepsilon^{2}\right)^{\frac{1}{2}}$,

where $F_{0}=\rho_{0} U^{3} N^{-1}$ is a constant in units of force per unit length and $\rho_{0}$ is the average density of seawater. This equation shows that the drag on the background current associated with generating lee waves grows in proportion to $J^{2}$ but decreases with decreasing hill length (increasing $\varepsilon$ ) until the hill is the same length as $\lambda_{\text {lee }}(\varepsilon=1)$, beyond which the steady-state drag vanishes. Addition of rotation with the Coriolis parameter $f$ adds a similar constraint, such that low wavenumber topography with wavenumbers satisfying $k<f / U$ also do not permit lee wave generation. Therefore, linear lee waves exist only for topography satisfying $f / U<k<N / U$. An important characteristic of the linear lee wave expression for drag is that it shows the drag is linearly proportional to the current (i.e., $F_{\text {lin }} \sim U$ ). This has important ramifications for ocean models that seek to parameterize lee-wave drag with quadratic drag laws that assume $F_{\text {lin }} \sim U^{2}$.

\section{Nonlinear and Nonhydrostatic Effects}

A significant fraction of abyssal hills are critical $(J \sim 1)$ or supercritical $(J>1)$ to the abyssal currents (Nikurashin et al., 2014; their Figure 9), and thus parameterizing the lee wave drag in these regions necessitates some corrections to account for nonlinearity. These are the regions in which existing wave drag schemes in HYCOM and elsewhere (e.g., Nikurashin and Ferrari, 2011; Scott et al., 2011) borrow from the literature on atmospheric lee waves (e.g., Snyder et al., 1985; Pierrehumbert, 1987; Garner, 2005) to assume that the lowest levels of the flow lack the kinetic energy to flow over a hill. When this occurs, the flow is blocked, and the wave-generating height of the hill is reduced such that the lee wave has an effective Froude number and the wave drag saturates (i.e., the wave drag no longer increases beyond some critical Froude number). The saturated wave drag comprises the linear component of the "scalarized" Garner scheme described in the Introduction.

In the framework of saturation theory, there is an effective bathymetry defined by the lowest over-topping streamline (hereafter LOTS). For atmospheric lee waves, which are well approximated by the hydrostatic limit, only the trough to crest height of the LOTS is necessary to predict the supercritical wave drag (Pierrehumbert, 1987). However, unlike atmospheric lee waves, those in the ocean are often strongly nonhydrostatic $(\varepsilon \sim \mathrm{O}(1))$, and thus it should be expected that the horizontal structure of the LOTS will be equally important for the supercritical wave drag. Additionally, the atmospheric wave drag schemes were developed for isolated mountain ridges, where the radiated lee wave, subject to the saturation hypothesis described above, is secondary to a violent hydraulic effect, or the "downslope windstorms" in the lee of the mountain, with as much as an eightfold increase in the drag over linear lee wave theory (Pierrehumbert, 1987). These windstorms are the motivation for both the hydraulic drag component in the "scalarized" Garner scheme and the choice to apply the drag in the bottom $500 \mathrm{~m}$ of the flow, where the wave breaking is assumed to deposit its momentum. However, neither downslope windstorms nor the resulting wave breaking are expected above periodic bathymetry (Baines, 1995; Welch, 2001), which suggests that applying these wave drag schemes to abyssal hills may not always be appropriate.

Nonhydrostatic simulations over a broad range of $J$ and $\varepsilon$ with sinusoidal bathymetry generally confirm the saturation hypothesis but reveal subtle details of the LOTS that further reduce the form drag (see Figure 3). Interestingly, a good model for the form drag with strong blocking can be obtained by using linear theory but with hill properties based on a LOTS that corresponds to a streamline that is one half of one lee wave wavelength above the bathymetry (recent work by authors Mayer and Fringer).

\section{The Effects of Unsteadiness}

Although linear lee wave theory assumes a steady flow, lee waves require a spin up period during which the assumption of steadiness fails. Simulations suggest that a useful timescale for the spin up process is the time it takes for a parcel to traverse the bathymetry, which we refer to as an excitation period $T_{e x}=L_{\text {hill }} / U$. Starting 
from rest, linear height simulations reach steady state within $3 T_{e x}$, while supercritical simulations establish blocking within $2 T_{e x}$ and the LOTS assumes a steady shape by $6 T_{e x}$. These general trends are evident in Figures 3 and 4. For typical abyssal currents, $T_{e x}$ is about 10 hours for hydrostatic bathymetry, and as short as 2 hours for nonhydrostatic bathymetry, which is very short relative to the timescale of mesoscale eddies (10-100 days), and in some cases shorter than even the tidal timescale. Indeed, even the hydrostatic spin up timescale is shorter than the 49-hour filter used to separate tidal and lowfrequency flows in HYCOM, as described in the Introduction. This suggests that the drag from quasi-steady lee waves could be important across a much larger temporal range of flows than currently parameterized in HYCOM. However, the interaction of tidal and low-frequency flows likely complicates the lee wave system and deserves further study.

During the spin up process, the bathymetry does work on the nearbottom flow in order to perturb it from its background state. Interestingly, nonhydrostatic linear theory offers a good estimate of the work required, even above supercritical bathymetry, where saturation reduces the drag after blocking sets in (see Figure 4). This suggests that existing wave drag parameterizations could employ a time-dependent modification based on the history of the background current in which the drag relaxes from the simple nonhydrostatic linear prediction to the nonhydrostatic saturation prediction over a timescale on the order of $T_{e x}$.

FIGURE 4. Time series of vertical momentum flux $F 15 \mathrm{~m}$ above the crest of the bathymetry (solid lines) and form drag (dashed lines), normalized by the constant value $\rho_{0} U^{3} N^{-1}$ (top), and the prediction of linear theory, $F_{\text {lin }}$ (bottom). The hills are all $2,000 \mathrm{~m}$ long $(\varepsilon=0.31)$ and vary in height from $2 \mathrm{~m}(J=0.02)$ to $200 \mathrm{~m}$ $(J=2)$. Note that for the supercritical simulations, during the first $T_{\text {ex }}$, there is a significant difference between the form drag and the vertical momentum flux aloft, indicating that some of the momentum fluxing away from the bathymetry is consumed by local hydraulic processes rather than radiating away as a wave.
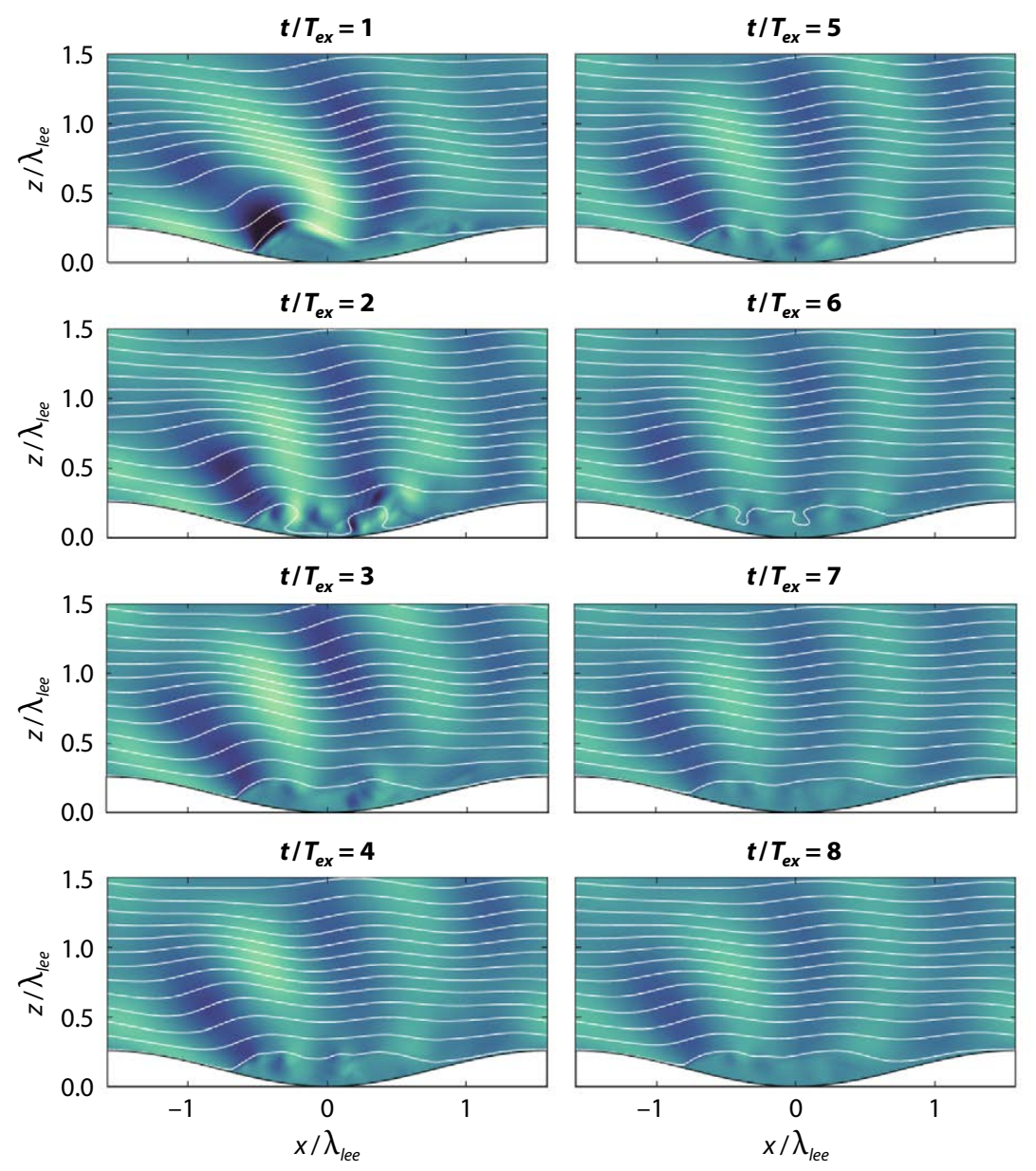

FIGURE 3. Nondimensional instantaneous vertical velocity field and streamlines (white lines) for a hill with $J=1.6$ and $\varepsilon=3.1$ at intervals of one excitation period $\left(T_{\mathrm{ex}}=L_{\text {hill }} / U\right)$. Owing to blocking, the effective hill height as measured by the lowest overtopping streamline is much smaller than the topographic high, leading to much weaker lee waves. The lowest overtopping streamline also displays vertical undulations with horizontal scale approximately equal to $\lambda_{\text {lee }}=2 \pi U / N$ that are evanescent and further reduce the drag. The colormap is "deep" from Thyng et al. (2016).
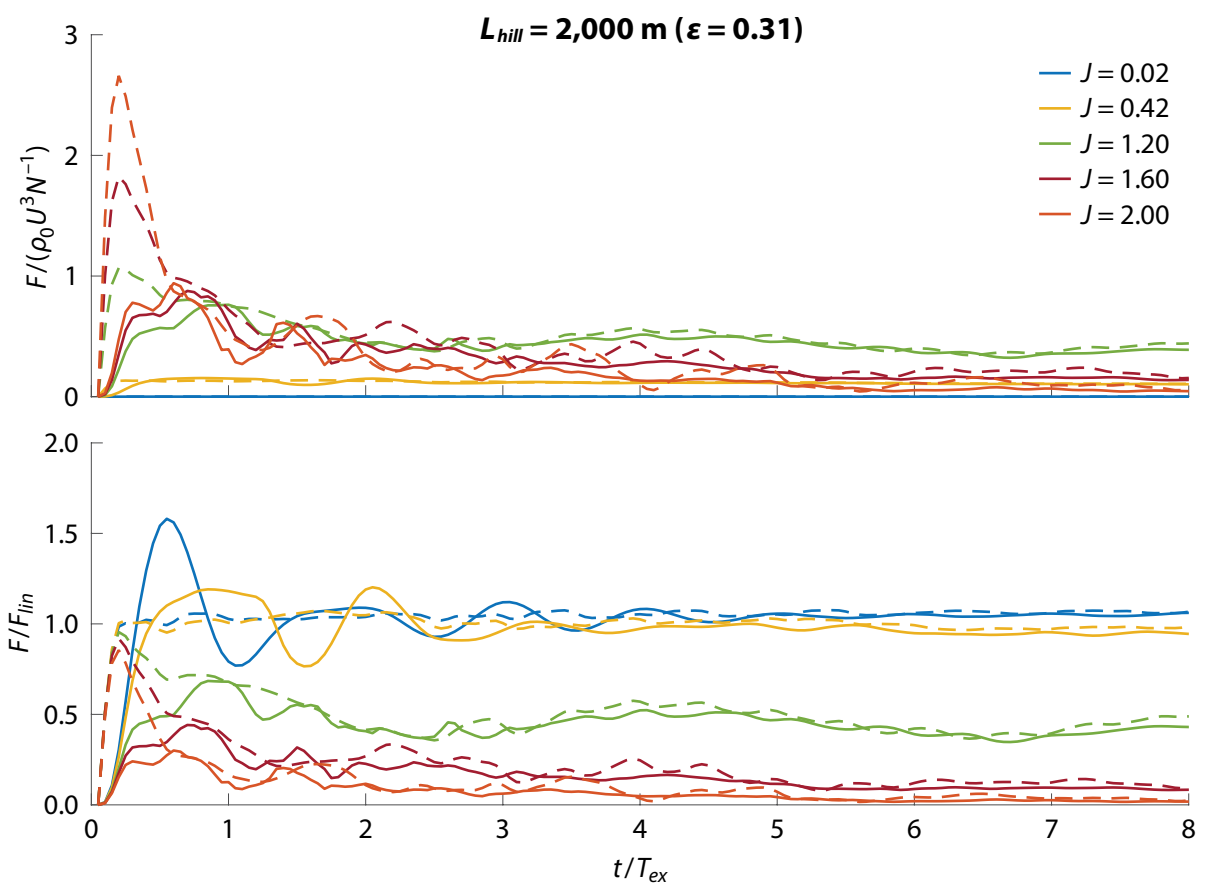
For supercritical height bathymetry, the difference between the drag during spin up and that after the establishment of blocking can be interpreted as the hydraulic drag because it arises from the nonlinear processes in the valley. After the establishment of the blocked layer, however, the form drag and the vertical momentum flux measured above the bathymetry aloft give nearly the same value (see Figure 4), indicating that supercritical height periodic bathymetry does not present the steady state system with a hydraulic drag, in contradiction of the "scalarized" Garner drag scheme. Thus, after spin up, the wave drag may not be acting as a drag on the bottom currents as assumed in HYCOM. Therefore, the details of how the drag is distributed over the water column may have important consequences for the observed decay of stratification and kinetic energy seen in the bottom layer of GCMs run with wave drag schemes as in Trossman et al. (2013, 2016, 2017).

\section{Parameterizing Lee Wave Drag Over Realistic Bathymetry}

Although the idealized simulations over sinusoidal bathymetry reveal potential limitations of existing parameterizations, simulations employing realistic topography are needed to develop parameterizations that can be directly applied to global models like HYCOM. An important consideration when parameterizing lee wave drag over realistic spectral topography is the potential for local changes in parameters by the large-scale flow that alters the lee wave generating capacity and resulting drag. In this regard, Klymak (2018) reports on three-dimensional (doubly periodic) simulations with flow over a full bathymetric spectrum that contained

\section{Dissipation Power Laws with $U$}

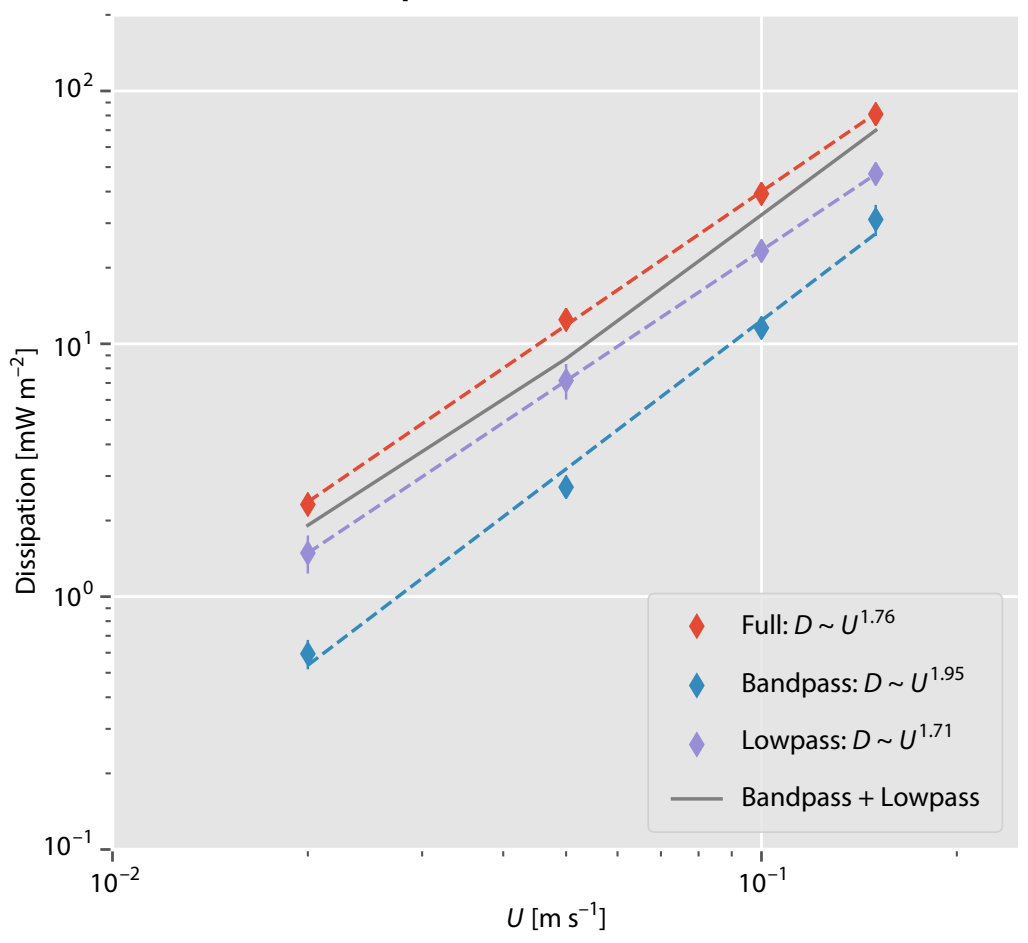

FIGURE 5. Dissipation D of flow over rough bathymetry for three different bathymetries, at four different mean flow speeds $U$ (same stratification and topographic amplitudes). Note that dissipation is equivalent to $\tau U$, where $\tau$ is the drag (stress) in these runs; hence, $\tau$ scales approximately as $\tau \sim U$. The simulations with just long wavelength bathymetry ("Lowpass") have substantially more dissipation than simulations with just small-scale bathymetry ("Bandpass") when the bathymetries are drawn from the same topographic spectrum. The "Full" simulation has all the bathymetry in it, and exhibits more dissipation than the sum of the two filtered simulations due to nonlinear effects (from Klymak, 2018).

wavenumbers that were smaller than the smallest wave-making wavenumber permitted by rotation $(f / U)$ and larger than the largest wave-making wavenumber permitted by nonhydrostatic effects $(N / U)$. Simulations were run with three bathymetries, namely the full bathymetry, a low-pass filtered bathymetry that eliminated all wavenumbers larger than $f / U$, and a bandpass filtered bathymetry that was restricted to wavenumbers within the wave-making regime $(f / U<k<N / U)$. No waves were expected for the low-pass filtered bathymetry because the topographic scales are too long to generate lee waves. However, the low wavenumber topography created local flow acceleration (increased $U$ ) that decreased the minimum wavenumber allowed for lee wave generation (decreased $f / U$ ). At the same time, the large amplitudes of the long topography increased the value of $J$ and the local nonlinearity of the flow, increasing the presence of blocking and hydraulic effects. The result was an increase in the bottom drag (and turbulent dissipation) by a factor of two over the bandpassed bathymetry (Figure 5). This highlights the difficulty in developing lee wave parameterizations given the nonlinear interaction between different wavenumbers in topography that is inherently spectral.

Although linear theory predicts linear dependence of the drag on the velocity, parameterizations of the form drag appear to be linear in velocity even for extremely nonlinear flows, as shown in Figure 5, which depicts behavior for hills with $J \sim \mathrm{O}(10)$. Based on Klymak et al. (2010), the scaling for hydraulically blocked form drag over an obstacle is proportional to $N h^{2} U(1+\pi / J)$, or $J^{2}(1+\pi / J)$ nondimensionally, a scaling that holds up very well for a wide range of topographic amplitudes and spectra. This particular scaling arises in part due to the acceleration of the flow over large-amplitude topography, which can significantly decrease the effective flow depth. Despite the strong nonlinearity, the scaling is similar to linear lee wave theory, in that it is linear in veloc- 
ity and quadratic in height. However, it has a higher-order correction for lower $J$ flows (i.e., $J=\mathrm{O}(1)$ ), where the result approaches the quadratic drag law typically used in the atmosphere. As an interesting note, the efforts of Garner (2005) and Trossman et al. (2013) to include long wavelength bathymetry justify a large drag due to blocking effects of nonpropagating internal motions on the findings from the atmospheric science literature, but in the end express their form drag as a linear drag in velocity, and use the quadratic drag only to come up with an appropriate (but tuned to the local expected velocity) drag coefficient.

\section{Lee Wave Drag and Eddies}

The hydraulic drag parameterization has been tested in an idealized wind-driven channel flow and shown to be better than a tuned quadratic drag coefficient across a range of topographic amplitudes (Figure 6). The influence of bottom drag in the Southern Ocean is to spin down eddies that transport wind-deposited momentum from the ocean surface to the seafloor. Hence, models that have more eddies will have weaker downstream transport (i.e., circumpolar current) because momentum is transferred more efficiently and the mean flow does not spin up as strongly (e.g., Abernathey and Cessi, 2014). This leads to the counterintuitive finding that increasing the bottom drag coefficient leads to stronger downstream transport (Marshall et al., 2017). In simulations with rough stochastic bathymetry in a channel, we find that downstream transport increases as the topographic height, and hence the bottom drag, increase (Figure 6). If we parameterize this effect in a coarserresolution model with smooth bathym- etry (Figure 6b) and a linear/quadratic hybrid drag law as proposed above, we get good agreement with the fine-scale simulation; if we instead run the coarse simulation with a quadratic drag law (and assume linearity in topographic height), we get a poor representation of the change of transport with increasing topographic height (Figure 6).

\section{SUMMARY AND DISCUSSION}

Inserting parameterized topographic wave drag into global models such as HYCOM simulations used for Navy global ocean forecasting impacts the modeled tides, currents, and mesoscale eddies. Wave drag impacts on the eddying general circulation are manifoldnear-bottom stratification and eddy kinetic energy are greatly reduced, the wave drag dissipates a substantial fraction of the wind power input, the sea surface

\section{(a) Temperature $\left[{ }^{\circ} \mathrm{C}\right]$}

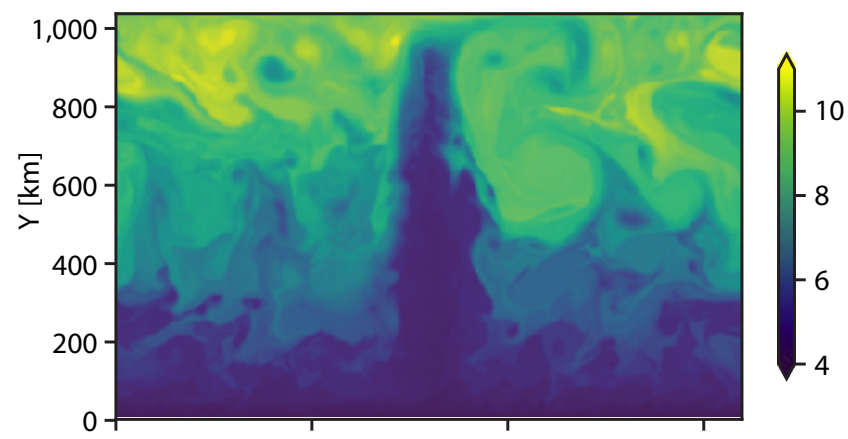

(b) Depth [m]

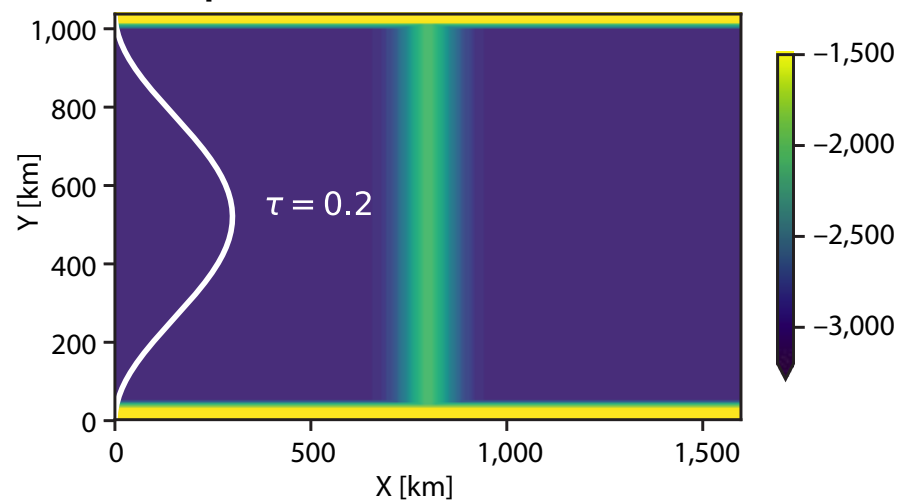

(c)

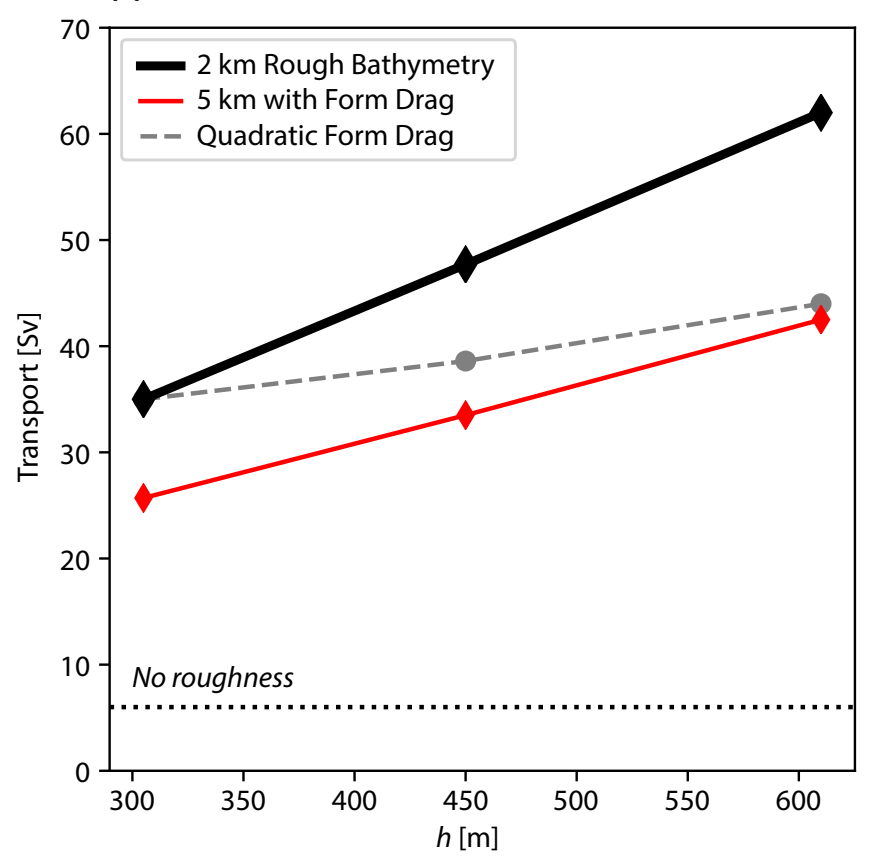

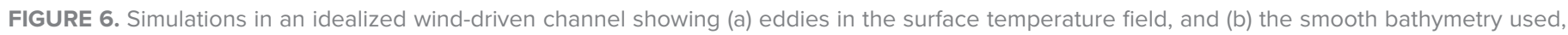

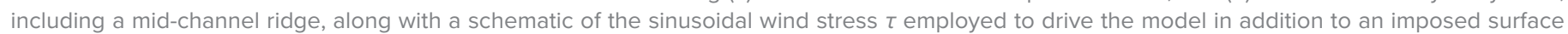

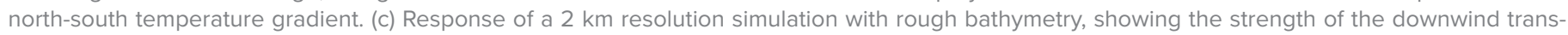

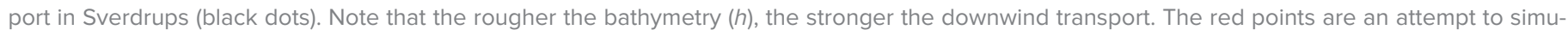

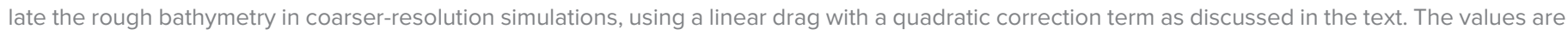

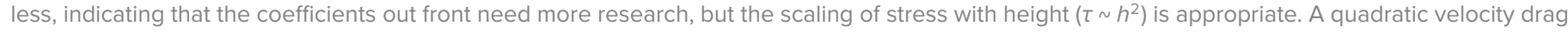

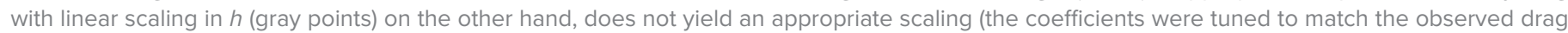
at $h=305 \mathrm{~m}$ ). The transport in a simulation with no roughness is given by the extra dashed horizontal line. 
height variance and surface kinetic energy are reduced by about $15 \%-23 \%$, and the model baroclinicity (vertical structure) is notably enhanced. The tidal energy budget, and the amplitudes of both barotropic and baroclinic tidal motions, are also strongly affected by the presence and the strength of wave drag. For simplicity, thus far we have examined the impacts of wave drag on low-frequency motions and tides in separate HYCOM simulations. Our HYCOM simulations with wave drag acting on eddies do not include explicit tides, while our HYCOM tidal simulations employ a filter so that wave drag acts only on tidal motions.

The importance of including wave drag in global models motivates the continued development of improved wave drag parameterizations from process studies based on both observations and models. The oceanographic and meteorological communities continue to progress in developing such parameterizations (e.g., Mayer and Fringer, 2017, and recent work of these authors; Olbers and Eden, 2017; Garner, 2018; Klymak, 2018; Olbers et al., 2019) and in implementing wave drag parameterizations (e.g., Eden and Olbers, 2017). Process studies with steady flows over sinusoidal bathymetry, outlined in detail here, suggest that the "scalarized" Garner (2005) wave drag scheme may require some modifications to account for the fact that hydraulic effects are nonexistent for periodic bathymetry after the blocked layer establishes, which occurs within the first few lee wave excitation periods. This also calls into question the practice of applying the wave drag to the bottom $500 \mathrm{~m}$ of the background current, because this is predicated on the hydraulic processes depositing the momentum in the bottom layer. Nevertheless, the component of the wave drag scheme relating to the linear lee wave radiated by the LOTS remains a powerful tool for predicting the wave drag, especially after accounting for its nonhydrostatic features.

Process studies of steady flows over realistic bathymetry, also described in detail here, confirm the notion from linear theory that the drag is linearly proportional to the current, even for strongly nonlinear flows. Parameterizations of the topographic wave drag in such flows appear to work well in certain cases, although they require a correction to account for more moderately nonlinear flows, for which the drag more closely follows a quadratic bottom drag law similar to that found in the atmospheric literature. Overall, while the process studies reveal promising parameterizations for the topographic wave drag in strongly blocked regimes, further research is needed to develop parameterizations that work over a broader parameter space. Most importantly, existing parameterizations fail to account for unsteady currents, meaning they likely incorrectly predict the lee wave drag in combined tidal/steady flows; some recent work (e.g., MacKinnon et al., 2019, and Callum Shakespeare, Australian National University, pers. comm., 2019) is beginning to tackle this important problem. @

\section{REFERENCES}

Abernathey, R., and P. Cessi. 2014. Topographic enhancement of eddy efficiency in baroclinic equilibration. Journal of Physical Oceanography 44:2,107-2,126, https://doi.org/10.1175/ jpo-d-14-0014.1.

Alford, M.H., and Z. Zhao. 2007. Global patterns of low-mode internal-wave propagation: Part I. Energy and energy flux. Journal of Physical Oceanography 37:1,829-1,848, https://doi.org/ 10.1175/JPO3085.1.

Ansong, J.K., B.K. Arbic, M.C. Buijsman, J.G. Richman, J.F. Shriver, and A.J. Wallcraft. 2015. Indirect evidence for substantial damping of low-mode internal tides in the open ocean. Journal of Geophysical Research Oceans 120:6,057-6,071, https://doi.org/ 10.1002/2015JC010998.

Arbic, B.K., and G.R. Flierl. 2004. Baroclinically unstable geostrophic turbulence in the limits of strong and weak bottom Ekman friction: Application to mid-ocean eddies. Journal of Physical Oceanography 34:2,257-2,273, https://doi.org/ 10.1175/1520-0485(2004)034<2257:BUGTIT> 2.0.CO;2.

Arbic, B.K., G.R. Flierl, and R.B. Scott. 2007. Cascade inequalities for forced-dissipated geostrophic turbulence. Journal of Physical Oceanography 37:1,470-1,487, https://doi.org/ 10.1175/JPO3067.1.

Arbic, B.K., and R.B. Scott. 2008. On quadratic bottom drag, geostrophic turbulence, and oceanic mesoscale eddies. Journal of Physical Oceanography 38:84-103, https://doi.org/ 10.1175/2007JPO3653.1.

Arbic, B.K., J.F. Shriver, P.J. Hogan, H.E. Hurlburt, J.L. McClean, E.J. Metzger, R.B. Scott, A. Sen, O.M. Smedstad, and A.J. Wallcraft. 2009. Estimates of bottom flows and bottom boundary layer dissipation of the oceanic general circulation from global high-resolution models. Journal of Geophysical Research 114, C02024, https://doi.org/10.1029/ $2008 \mathrm{JC} 005072$.

Arbic, B.K., A.J. Wallcraft, and E.J. Metzger. 2010. Concurrent simulation of the eddying general circulation and tides in a global ocean model. Ocean Modelling 32:175-187, https://doi.org/10.1016/ j.ocemod.2010.01.007.

Arbic, B.K., M.H. Alford, J.K. Ansong, M.C. Buijsman, R.B. Ciotti, J.T. Farrar, R.W. Hallberg, C.E. Henze, C.N. Hill, C.A. Luecke, and others. 2018. A primer on global internal tide and internal gravity wave continuum modeling in $\mathrm{HYCOM}$ and $\mathrm{MITg} \mathrm{cm}$. Pp. 307-392 in New Frontiers in Operational Oceanography. E. Chassignet, A. Pascual, J. Tintore, and J. Verron, eds, GODAE OceanView, https://doi.org/10.17125/gov2018.ch13.

Baines, P.G. 1995. Topographic Effects in Stratified Flows. Cambridge Monographs on Mechanics, Cambridge University Press, Cambridge.

Bell, T.H. 1975. Lee waves in stratified flows with simple harmonic time dependence. Journal of Fluid Dynamics 67:705-722, https://doi.org/10.1017/ S0022112075000560.

Buijsman, M.C., J.K. Ansong, B.K. Arbic, J.G. Richman, J.F. Shriver, P.G. Timko, A.J. Wallcraft, C.B. Whalen, and Z. Zhao. 2016. Impact of parameterized internal wave drag on the semidiurnal energy balance in a global ocean circulation model. Journal of Physical Oceanography 46:1,399-1,419, https://doi.org/ 10.1175/JPO-D-15-0074.1.

Chassignet, E.P., H.E. Hurlburt, E.J. Metzger, O.M. Smedstad, J.A. Cummings, G.R. Halliwell, R. Bleck, R. Baraille, A.J. Wallcraft, C. Lozano, and others. 2009. US GODAE: Global ocean prediction with the HYbrid Coordinate Ocean Model (HYCOM). Oceanography 22(2):64-76, https://doi.org/10.5670/oceanog.2009.39.

Cummings, J.A. 2005. Operational multivariate ocean data assimilation. Quarterly Journal of the Royal Meteorological Society 121:3,583-3,604, https://doi.org/10.1256/qj.05.105.

Dossman, Y., M.G. Rosevear, R.W. Griffiths,

A. McC. Hogg, G.O. Hughes, and M. Copeland. 2016. Experiments with mixing in stratified flow over a topographic ridge. Journal of Geophysical Research 121:6,961-6,977, https://doi.org/10.1002/ 2016JC011990.

Eden, C., and D. Olbers. 2017. A closure for internal wave-mean flow interaction: Part II. Wave drag. Journal of Physical Oceanography 47:1,403-1,412, https://doi.org/10.1175/JPO-D-16-0056.1.

Garner, S.T. 2005. A topographic drag closure built on an analytical base flux. Journal of the Atmospheric Sciences 62:2,302-2,315, https://doi.org/10.1175/ JAS3496.1.

Garner, S.T. 2018. Ground-truth model evaluation of subgrid orographic base-flux parameterization. Journal of the Atmospheric Sciences 75:3,653-3,670, https://doi.org/10.1175/ JAS-D-17-0368.1.

Goff, J.A. 2010. Global prediction of abyssal hill root-mean-square heights from small-scale altimetric gravity variability. Journal of Geophysical Research 115, B12104, https://doi.org/10.1029/ $2010 J B 007867$.

Goff, J.A., and B.K. Arbic. 2010. Global prediction of abyssal hill roughness statistics for use in ocean models from digital maps of paleo-spreading rate, paleo-ridge orientation, and sediment thickness. Ocean Modelling 32:36-43, https://doi.org/ 10.1016/j.ocemod.2009.10.001.

Jayne, S.R., and L.C. St. Laurent. 2001. Parameterizing tidal dissipation over rough topography. Geophysical Research Letters 28(5):811-814, https://doi.org/10.1029/2000GL012044.

Johnston, T.M.S., J.A. MacKinnon, P.L. Colin, P.J. Haley Jr., P.F.J. Lermusiaux, A.J. Lucas, M.A. Merrifield, S.T. Merrifield, C. Mirabito, J.D. Nash, and others. 2019. Energy and momentum lost to wake eddies and lee waves gener- 
ated by the North Equatorial Current and tidal flows at Peleliu, Palau. Oceanography 32(4):110-125, https://doi.org/10.5670/oceanog.2019.417.

Klymak, J.M., S. Legg, and R. Pinkel. 2010. High-mode stationary waves in stratified flow over large obstacles. Journal of Fluid Mechanics 644:312-336, https://doi.org/10.1017/S0022112009992503.

Klymak, J.M. 2018. Nonpropagating form drag and turbulence due to stratified flow over largescale abyssal hill topography. Journal of Physical Oceanography 48:2,383-2,395, https://doi.org/ 10.1175/jpo-d-17-0225.1.

Kunze, E. 2017. Internal-wave-driven mixing: Global geography and budgets. Journal of Physical Oceanography 47:1,325-1,345, https://doi.org/ 10.1175/JPO-D-16-0141.1.

Lott, F., and M.J. Miller. 1997. A new subgrid-scale orographic drag parametrization: Its formulation and testing. Quarterly Journal of the Royal Meteorological Society 123(537):101-127, https://doi.org/10.1002/qj.49712353704.

MacKinnon, J.A., M.H. Alford, G. Voet, K.L. Zieden, T.M.S. Johnston, M. Siegelman, S. Merrifield, and M. Merrifield. 2019. Eddy wake generation from broadband currents near Palau. Journal of Geophysical Research 124(7):4,891-4,903, https://doi.org/10.1029/2019JC014945.

Marshall, D.P., M. H.P. Ambaum, J.R. Maddison, D.R. Munday, and L. Novak. 2017. Eddy saturation and frictional control of the Antarctic Circumpolar Current. Geophysical Research Letters 44:286-292, https://doi.org/10.1002/ $2016 \mathrm{gl071702}$

Mayer, F.T., and O.B. Fringer. 2017. An unambiguous definition of the Froude number for lee waves in the deep ocean. Journal of Fluid Mechanics 831, https://doi.org/10.1017/jfm.2017.701.

Melet, A., M. Nikurashim, C. Muller, S. Falahat, J. Nycander, P.G. Timko, B.K. Arbic, and J.A. Goff. 2013. Internal tide generation by abyssal hills using analytical theory. Journal of Geophysical Research 118(11):6,303-6,318, https://doi.org/ 10.1002/2013JC009212.

Nikurashin, M., and R. Ferrari. 2011. Global energy conversion rate from geostrophic flows into internal lee waves in the deep ocean. Geophysical Research Letters 38:1-6, https://doi.org/ 10.1029/2011GL046576.

Nikurashin, M., R. Ferrari, N. Grisouard, and K. Polzin. 2014. The impact of finite-amplitude bottom topography on internal wave generation in the Southern Ocean. Journal of Physical Oceanography 44:2,938-2,950, https://doi.org/ 10.1175/JPO-D-13-0201.1.

Olbers, D., and C. Eden. 2017. A closure for internal wave-mean flow interaction Part I. Energy conversion. Journal of Physical Oceanography 47:1,389-1,401, https://doi.org/ 10.1175/JPO-D-16-0054.1.

Olbers, D., C. Eden, E. Becker, F. Pollmann, and J. Jungclaus. 2019. The IDEMIX model: Parameterization of internal gravity waves for circulation models of ocean and atmosphere. Pp. 87-125 in Energy Transfers in Atmosphere and Ocean. Mathematics of Planet Earth, vol 1. C. Eden and A. Iske, eds, Springer, https://doi.org/ 10.1007/978-3-030-05704-6_3.

Pearson, B., B. Fox-Kemper, S. Bachman, and F. Bryan. 2017. Evaluation of scale-aware subgrid mesoscale eddy models in a global eddy-rich model. Ocean Modelling 115:42-58, https://doi.org/10.1016/ j.ocemod.2017.05.007.

Pierrehumbert, R.T. 1987. An essay on the parameterization of orographic gravity wave drag. Pp. 251-282 in the proceedings of Seminar/ Workshop on Observations, Theory and Modelling of Orographic Effects, vol. 1. ECMWF, Shinfield Park, Reading, UK.

Scinocca, J.F., and N.A. McFarlane. 2000. The parametrization of drag induced by stratified flow over anisotropic orography.
Quarterly Journal of the Royal Meteorological Society 126(568):2,353-2,393, https://doi.org/ 10.1002/qj.49712656802.

Scott, R.B., and F. Wang. 2005. Direct evidence of an oceanic inverse kinetic energy cascade from satellite altimetry. Journal of Physical Oceanography 35:1,650-1,666, https://doi.org/ 10.1175/JPO2771.1.

Scott, R.B., J.A. Goff, A.C. Naveira-Garabato, and A.J.G. Nurser. 2011. Global rate and spectral characteristics of internal gravity wave generation by geostrophic flow over topography. Journal of Geophysical Research 116, C09029, https://doi.org/ 10.1029/2011JC007005

Sen, A., R.B. Scott, and B.K. Arbic. 2008. Global energy dissipation rate of deep-ocean lowfrequency flows by quadratic bottom boundary layer drag: Computations from current meter data. Geophysical Research Letters 35, L09606, https://doi.org/10.1029/2008GL033407.

Shriver, J.F., B.K. Arbic, J.G. Richman, R.D. Ray, E.J. Metzger, A.J. Wallcraft, and P.G. Timko. 2012 An evaluation of the barotropic and internal tides in a high resolution global ocean circulation model. Journal of Geophysical Research 117, C10024, https://doi.org/10.1029/2012JC008170.

Smith, W.H.F., and D.T. Sandwell. 1997. Global seafloor topography from satellite altimetry and ship depth soundings. Science 277:1,956-1,962 https://doi.org/10.1126/science.277.5334.1956.

Snyder, W.H., R.S. Thompson, R.E. Eskridge, R.E. Lawson, I.P. Castro, J. Lee, J., J.C. Hunt, and Y. Ogawa. 1985. The structure of strongly stratified flow over hills: Dividing-streamline concept. Journal of Fluid Mechanics 152:249-288, https://doi.org/10.1017/S0022112085000684.

St. Laurent, L.C., H.L. Simmons, and S.R. Jayne. 2002. Estimating tidally driven mixing in the deep ocean. Geophysical Research Letters 29(23):21-1-21-4, https://doi.org/10.1029/2002GL015633.

Taylor, G.I. 1919. Tidal friction in the Irish Sea. Philosophical Transactions of the Royal Society of London A 220:1-93, https://doi.org/10.1098/ rspa.1919.0059.

Thompson, A.F., and W.R. Young. 2006. Scaling baroclinic eddy fluxes: Vortices and energy balance. Journal of Physical Oceanography 36:720-738 https://doi.org/10.1175/JPO2874.1.

Thurnherr, A.M., and K.G. Speer. 2003. Boundary mixing and topographic blocking on the MidAtlantic Ridge in the South Atlantic. Journal of Physical Oceanography 33:848-862, https://doi.org/10.1175/1520-0485(2003)33 $<848$ :BMATBO>2.0.CO;2.

Thyng, K.M., C.A. Greene, R.D. Hetland, H.M. Zimmerle, and S.F. DiMarco. 2016. True colors of oceanography: Guidelines for effective and accurate colormap selection. Oceanography 29(3):9-13, https://doi.org/10.5670/ oceanog.2016.66.

Timko, P.G., B.K. Arbic, J.A. Goff, J.K. Ansong, W.H.F. Smith, A. Melet, and A.J. Wallcraft. 2017 Impact of synthetic abyssal hill roughness on resolved motions in numerical global ocean tide models. Ocean Modelling 112:1-16, https://doi.org/ 10.1016/j.ocemod.2017.02.005.

Trossman, D.S., B.K. Arbic, S.T. Garner, J.A. Goff, S.R. Jayne, E.J. Metzger, and A.J. Wallcraft. 2013. Impact of parameterized lee wave drag on the energy budget of an eddying global ocean model. Ocean Modelling 72:119-142, https://doi.org/ 10.1016/j.ocemod.2013.08.006.

Trossman, D.S., S. Waterman, K.L. Polzin, B.K. Arbic, S.T. Garner, A.C. Naveira-Garabato, and K.L. Sheen. 2015. Internal lee wave closures: Parameter sensitivity and comparison to observations. Journal of Geophysical Research 120:7,997-8,019, https://doi.org/10.1002/2015JC010892.

Trossman, D.S., B.K. Arbic, J.G. Richman, S.T. Garner, S.R. Jayne, and A.J. Wallcraft. 2016. Impact of topographic internal lee wave drag on an eddying global ocean model. Ocean Modelling 97:109-128, https://doi.org/10.1016/j.ocemod.2015.10.013.
Trossman, D.S., B.K. Arbic, D.N. Straub, J.G. Richman, E.P. Chassignet, A.J. Wallcraft, and X. Xu. 2017. The role of rough topography in mediating impacts of bottom drag in eddying ocean circulation models. Journal of Physical Oceanography 47:1,941-1,959, https://doi.org/10.1175/JPO-D-16-0229.1.

Waterhouse, A.F., J.A. MacKinnon, J.D. Nash, M.H. Alford, E. Kunze, H.L. Simmons, K.L. Polzin, L.C. St. Laurent, O.M. Sun, R. Pinkel, and others. 2014. Global patterns of diapycnal mixing from measurements of the turbulent dissipation rate. Journal of Physical Oceanography 44:1,854-1,872, https://doi.org/10.1175/JPO-D-13-0104.1.

Welch, W.T., P. Smolarkiewicz, R. Rotunno, and B.A. Boville. 2001. The large-scale effects of flow over periodic mesoscale topography. Journal of Atmospheric Science 58(12):1,477-1,492, https://doi.org/10.1175/1520-0469(2001)058 $<1477:$ TLSEOF>2.0.CO;2.

\section{ACKNOWLEDGMENTS}

We acknowledge helpful comments from the guest editors and two anonymous reviewers. BKA and DST gratefully acknowledge support from National Science Foundation (NSF) grant OCE-0960820 and Office of Naval Research (ONR) grants N00014-11-10487 and N00014-17-1-2958. OBF and FTM gratefully acknowledge support from ONR grant N00014 16-1-2256. Grants of computer time were provided by the Department of Defense (DoD) High Performance Computing Modernization Program and by the National Center for Atmospheric Research (NCAR) Yellowstone university allocations. We would like to acknowledge high-performance computing support from Yellowstone (ark:/85065/d7wd3xhc) provided by NCAR's Computational and Information Systems Laboratory, sponsored by NSF. We would also like to acknowledge high-performance computing support from the US Army Engineer Research and Development Center DoD Supercomputing Resource Center in Vicksburg, Mississippi.

\section{AUTHORS}

Brian K. Arbic (arbic@umich.edu) is Professor, Department of Earth and Environmental Sciences, University of Michigan, Ann Arbor, MI, USA

Oliver B. Fringer is Professor, Department of Civil and Environmental Engineering, Stanford University, Stanford, CA, USA. Jody M. Klymak is Professor, School of Earth and Ocean Sciences and Department of Physics and Astronomy, University of Victoria, Victoria, BC, Canada. Frederick T. Mayer is PhD Candidate, Department of Civil and Environmental Engineering, Stanford University, Stanford, CA, USA David S. Trossman is Research Associate, Oden Institute for Computational Engineering and Sciences, The University of Texas at Austin, Austin, TX, USA Peiyun Zhu is PhD Candidate, Department of Civil and Environmental Engineering, Stanford University, Stanford, CA, USA.

\section{ARTICLE CITATION}

Arbic, B.K., O.B. Fringer, J.M. Klymak, F.T. Mayer D.S. Trossman, and P. Zhu. 2019. Connecting process models of topographic wave drag to global eddying general circulation models. Oceanography 32(4):146-155, https://doi.org/10.5670/ oceanog. 2019.420.

\section{COPYRIGHT \& USAGE}

This is an open access article made available unde the terms of the Creative Commons Attribution 4.0 International License (https://creativecommons.org/ licenses/by/4.0/), which permits use, sharing, adaptation, distribution, and reproduction in any medium or format as long as users cite the materials appropriately, provide a link to the Creative Commons license, and indicate the changes that were made to the original content. 